\title{
INFLUENCE OF 3-MONTH THERAPY USING THE NEURO-ORTHOPAEDIC SUIT ATLANT ON GAIT CHARACTERISTICS IN PRESCHOOL CHILDREN WITH SPASTIC CEREBRAL PALSY
}

\author{
Helena Gapeyeva, Paulin Mitt, JaAn Ereline, Mati PäÄsuke \\ Institute of Exercise Biology and Physiotherapy, University of Tartu, Tartu, Estonia
}

\begin{abstract}
Different kinds of physical therapy are used in medical rehabilitation of neurological patients with motor deficiency: partial body weight-supported treadmill training, driven gait orthosis, neuromuscular electrical stimulation and neuroorthopaedic suit therapies. Neuro-orthopaedic pneumosuit (NOPS) Atlant (Dynaforce, Russia) creates a muscle framework by dynamic proprioceptive stimulation, stabilizing the trunk and the extremities, reducing pathological synergies and normalizing patient's motor activity. The aim of the present study was to investigate the influence of 3-month therapy using the NOPS Atlant on gait characteristics in preschool children with spastic form of cerebral palsy (CP). Six CP children with spasticity of lower extremities with (mean \pm SE) age of $5.2 \pm 0.8$ years participated in the present study. Children had NOPS Atlant therapy sessions during three months, supervised by an experienced physiotherapist. The kinematic and kinetic characteristics of gait were measured using 3-D movement analysis system Elite Clinic (BTS S.p.A., Italy). After 3-month therapy using the NOPS Atlant, significant increase $(7.9 \%)$ of the stride length of gait was found as compared with the initial data. Children with spastic CP demonstrated significant improvement of range of motion of hip joint abduction, decrease of knee joint external rotation, as well as positive changes in foot progression angle during gait. In conclusion, motor function re-activation during gait in preschool children with spasticity caused by cerebral palsy was noted after 3-month therapy using the NOPS Atlant. However, future research is needed to elucidate mechanisms of neurodynamic therapy effect on motor ability in children with CP.
\end{abstract}

Keywords: cerebral palsy; spasticity; physical therapy; walking 


\section{INTRODUCTION}

Cerebral paralysis (CP) causes numerous impairments of neuromuscular and skeletal systems like spasticity, dystonia, joint contractures, abnormal bone growth, body balance and selective motor control impairments [9]. CP is a frequent cause of motor impairments in childhood, it occurs in 2-3 children per 1000 livebirths [21]. Most frequent motor impairment in CP children is spasticity [6], which is characterised by increase of velocity-dependent tonic reflex accompanied by overnormal stretch-reflex and produced by hyperirritability of stretch-reflex due to higher motor neuron syndrome [14]. A recent study on Australian population-based CP register identified 2956 individuals (1658 males, 1298 females, born in 1970-2003) with spastic CP [17]. The results showed that among individuals born $<32$ weeks, $48 \%$ had diplegia, whereas for children born $\geq 32$ weeks the respective number was $24 \%$. An increased proportion of spastic diplegia in relation to quadriplegia and wide variations across studies in the proportion of diplegia (range 34-90\%) and bilateral spastic CP (range 51-86\%) were revealed.

Children with hemiparesis began to walk at the age of 18-21 months, $75-85 \%$ of children with spastic diplegia walked at the age of 4 years, but only $10 \%$ of children with spastic tetraparesis walked at the age of 7 years [22]. Despite the fact that a significant part of children have good cognitive abilities and have independent social life, numerous children remain dependent on additional motion devices such as rulators or crutches [1]. Study of Harvey et al. [10] found that children at Level III according to Gross Motor Function Classification System (GMFCS) who had undergone multilevel surgery, showed more changes in mobility as compared with children at Level I/II at home and in school activities. Wheelchairs were most commonly used in the community before and after single-event multijoint surgery.

Different modalities of physical therapy are used in medical rehabilitation of neurological patients with motor deficiency: partial body weight-supported treadmill training $[4,16]$, driven gait orthosis [3], neuromuscular electrical stimulation [12] and neuro-orthopaedic suit therapies [2, 8, 19]. Neuro-orthopaedic pneumosuit (NOPS) Atlant (Dynaforce, Russia) creates a muscle framework by dynamic proprioceptive stimulation stabilizing the trunk and the extremities, reducing pathological synergies and normalizing patient's motor activity. Previously, the effect of the NOPS Atlant has been studied in adult patients with different neurologic or orthopaedic pathologies [13]. To our knowledge, the present research includes data of the first study where NOPS Atlant has been used in physical therapy for children with CP, aged 3-7 years. The aim of the present study was to investigate the influence of 3-month therapy using the NOPS Atlant on gait characteristics in preschool children with spastic CP. 


\section{MATERIALS AND METHODS}

\section{Subjects}

Six CP children (five girls and one boy, GMFCS level II-III) with spasticity of lower extremities aged 3-7 years participated in the present study before and 3 months after therapy using the NOPS Atlant (Table 1).

Table 1. Anthropometric data of subjects (mean \pm SE)

\begin{tabular}{lcc}
\hline Characteristics & Before therapy & After therapy \\
\hline Age (year) & $5.20 \pm 0.80$ & $5.40 \pm 0.75$ \\
\hline Body mass $(\mathrm{kg})$ & $20.70 \pm 2.11$ & $21.76 \pm 2.41$ \\
\hline Body height $(\mathrm{m})$ & $1.13 \pm 0.04$ & $1.15 \pm 0.04$ \\
\hline Body mass index $\left(\mathrm{kg} / \mathrm{m}^{2}\right)$ & $15.90 \pm 0.65$ & $16.24 \pm 0.86$ \\
\hline Lower extremity length $(\mathrm{m}), \mathrm{R}$ & $0.58 \pm 0.03$ & $0.59 \pm 0.03$ \\
\hline Lower extremity length $(\mathrm{m}), \mathrm{L}$ & $0.58 \pm 0.03$ & $0.59 \pm 0.03$ \\
\hline
\end{tabular}

Note: $\mathrm{R}$ - right, $\mathrm{L}$ - left; $\mathrm{p}>0.05$

All participants were recruited from one nursery school of Tartu, Estonia. Organizers of the study excluded the recruitment of children with severe speech and language disorders or problems in their mental or physical development. Inclusion criteria were: spastic diplegia syndrome, ability to walk at least $20 \mathrm{~m}$ with or without additional devices, absence of epileptic cramps, good cognitive ability, and absence of Botox injections during the recent 3 months.

The study carried the approval of the Ethics Committee of the University of Tartu. A written informed consent from the children's parents and each child's assent were obtained for participation in the present study.

Measurements were performed partly in the nursery school and partly at the Laboratory of Kinesiology and Biomechanics, University of Tartu. All assessments were carried out in the mornings to minimize the possibility of fatigue. All tests were performed individually, by appropriately qualified therapists, who were unaware of the children's group assignment. The subjects were given instructions before data collection and the testing procedures were demonstrated, followed by practice session to familiarize the subjects with the procedures.

\section{Intervention}

The children received physical therapy and exercise therapy using the NOPS Atlant (Figures 1A and 1B) during the period of three months in nursery 
school, supervised by an experienced physiotherapy specialist. Suits have been used in accordance with height and chest dimensions of each child individually.
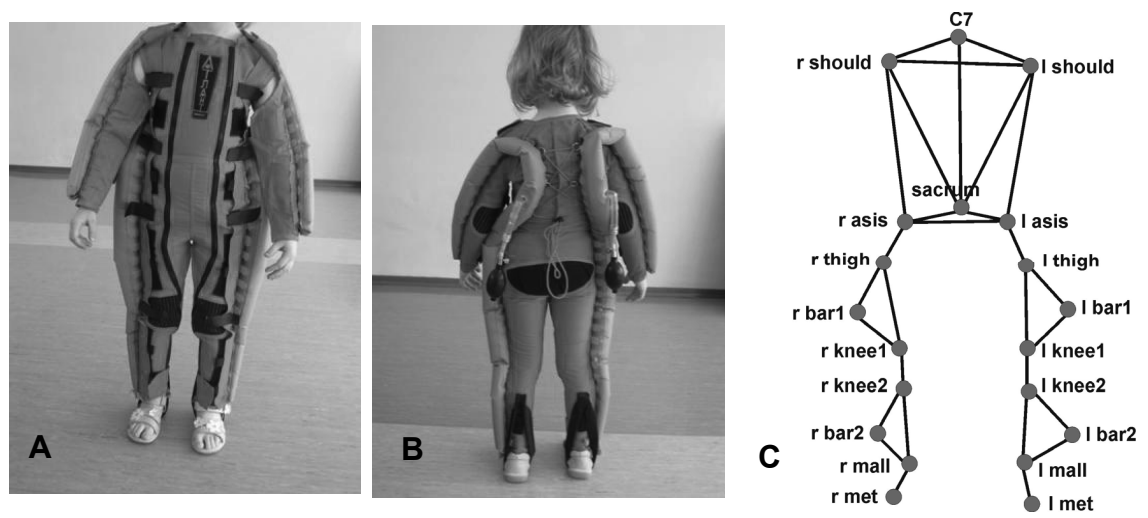

Figure 1. Neuro-orthopaedic pneumosuit Atlant - anterior (A) and posterior (B) view and biomechanic model of trunk and lower extremities (C).

The mean $( \pm \mathrm{SE})$ number of therapy sessions using the NOPS Atlant was $12.2 \pm 1.9$ during the treatment period, and each session increased progressively from $10 \mathrm{~min}$ at the beginning of therapy to $35 \mathrm{~min}$ at the end of the therapy period. Therapy sessions using the NOPS Atlant were planned individually and aimed at improving body balance, the symmetry of movements and posture, as well as increasing muscle strength, influencing muscle tone and gait pattern improvement.

\section{Methods}

The kinematic characteristics of gait were measured using 3-dimensional movement analysis system Elite Clinic (BTS S.p.A., Italy). Twenty passive reflecting markers were attached to the selected points of the body according to the Helen Hayes protocol using the Davis biomechanical model [5] (Figure 1C). Gait temporal (stance time, swing time, double support time, stride time, cadence) and distance characteristics (step length, stride length, step width, velocity for each leg, mean velocity) as well as range of motion (ROM) of hip, knee and ankle joints were calculated. Three to six trials of gait with comfortable velocity for each child were recorded and the best trial was taken for analysis [7]. All studies were performed in same time of day (from 10 to 12 a.m.). 


\section{Statistical analysis}

Data are means and standard error of mean (SE). Student's paired t-test was used to find differences of data before and after 3-month NOPS therapy. A level of $\mathrm{p}<0.05$ was selected to indicate statistical significance.

\section{RESULTS}

No significant differences in subjects' anthropometric data as compared before therapy and after three months were observed (Table 1). After 3-month therapy using the NOPS Atlant the temporal characteristics of gait did not differ significantly $(\mathrm{p}>0.05)$ as compared with the pre-therapy period (Table 2$)$. A significant $(p<0.05)$ increase $(7.91 \%)$ of the stride length of gait was found as compared with the initial data (Table 3 ). Decline of difference in gait velocity between right and left leg was noted - from $5.10 \%$ before therapy to $0.98 \%$ after 3-month NOPS Atlant therapy.

Table 2. Temporal characteristics of gait (mean \pm SE)

\begin{tabular}{lcc}
\hline Characteristics & Before therapy & After 3-month therapy \\
\hline Stance time (\%), R & $60.98 \pm 1.59$ & $61.26 \pm 0.85$ \\
\hline Stance time (\%), L & $59.10 \pm 1.47$ & $57.96 \pm 0.86$ \\
\hline Swing time (\%), R & $39.02 \pm 1.59$ & $39.02 \pm 1.59$ \\
\hline Swing time (\%), L & $40.90 \pm 1.47$ & $42.04 \pm 0.86$ \\
\hline Double support time (\%), R & $10.34 \pm 1.04$ & $11.02 \pm 1.05$ \\
\hline Double support time (\%), L & $9.44 \pm 1.36$ & $9.46 \pm 0.66$ \\
\hline Cadence (step/min) & $137.74 \pm 10.37$ & $148.52 \pm 13.34$
\end{tabular}

Note: data are $\%$ of gait cycle; $R$ - right, $L-$ left; $p>0.05$

Table 3. Distance characteristics of gait (mean $\pm S E$ )

\begin{tabular}{lcc}
\hline Characteristics & Before therapy & After 3-month therapy \\
\hline Step length $(\mathrm{m}), \mathrm{R}$ & $0.39 \pm 0.04$ & $0.42 \pm 0.04$ \\
\hline Step length $(\mathrm{m}), \mathrm{L}$ & $0.98 \pm 0.14$ & $1.02 \pm 0.15$ \\
\hline Velocity $(\mathrm{m} / \mathrm{s}), \mathrm{R}$ & $0.93 \pm 0.13$ & $1.03 \pm 0.15$ \\
\hline Velocity $(\mathrm{m} / \mathrm{s}), \mathrm{L}$ & $0.98 \pm 0.14$ & $1.02 \pm 0.15$ \\
\hline Stride length $(\mathrm{m}), \mathrm{R}$ & $0.75 \pm 0.06$ & $0.82 \pm 0.07^{\star}$ \\
\hline Stride length $(\mathrm{m}), \mathrm{L}$ & $0.76 \pm 0.07$ & $0.82 \pm 0.07^{\star}$ \\
\hline Step width $(\mathrm{m}), \mathrm{R}$ & $0.10 \pm 0.01$ & $0.10 \pm 0.01$ \\
\hline Step width $(\mathrm{m}), \mathrm{L}$ & $0.10 \pm 0.01$ & $0.09 \pm 0.01$
\end{tabular}

Note: $\mathrm{R}$-right, L-left; ${ }^{*} \mathrm{p}<0.05$ as compared before therapy 

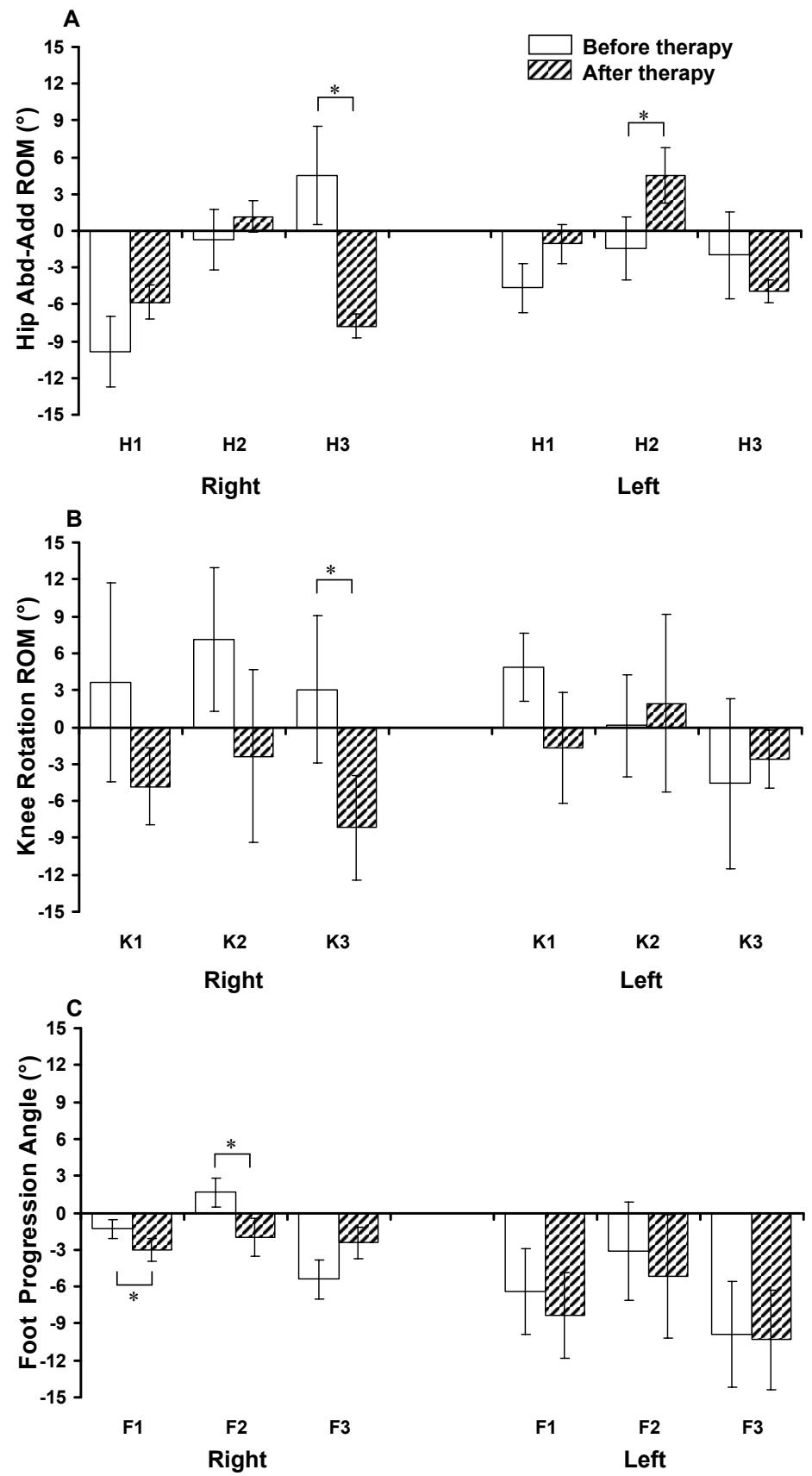

Figure 2. Hip abduction-adduction ROM (A), knee joint rotation ROM (B) and foot progression angle $(C)$ during gait before and after 3-month neuro-orthopaedic pneumosuit Atlant therapy in children with spastic CP (mean $\pm S E)$. 1 - initial contact of the foot with the ground, 2- maximal angle in stance, 3 - maximal angle in swing; ${ }^{*} p<0.05$. 
Significant increase $(\mathrm{p}<0.05)$ of right hip abduction ROM (Figure $2 \mathrm{~A})$ and knee joint external rotation ROM (Figure 2B) in swing phase as well as increase of foot progression angle (Figure $2 \mathrm{C}$ ) in stance phase during gait were noted after 3-month NOPS therapy as compared to the pre-therapy period.

No significant differences emerged in kinematic characteristics of other joints between pre- and post-therapy period.

\section{DISCUSSION}

The main results of the 3-month application of the NOPS Atlant in preschool children with moderate level of $\mathrm{CP}$ were: (1) children demonstrated significant improvement of ROM of hip abduction and knee external rotation as well as increase of foot progression angle, and (2) stride length of gait was increased as compared to the initial data.

The qualitative classifications of gait in children with spastic diplegia have been more widely used and different classifications have been applied for this aim. Main concerns have appeared about the validity of classifications, which are not based on quantitative data [18]. The results of the present study are based on standard gait instrumental kinematic analysis and improvement of gait characteristics have been found in preschool children with $\mathrm{CP}$ after using NOPS Atlant. In the study of Bailes et al. [2] the influence of 3-week TheraSuit ${ }^{\text {tx }}$ method on gait in two children with spastic diplegia syndrome was analysed. The patients performed trainings five days a week and the duration of the one training was 3-4 hours. After training, improvement of gait characteristics (speed and cadence, movement pattern) and of posture was noted. Sologubov [20] investigated a 20-day orthopaedic suit therapy that was performed using Adeli-92 load suit in children with spastic diplegia syndrome aged 10 to 18 years; each session lasted for one hour. After Adeli suit therapy the improvement of postural steadiness and increase of ROM and length of step during gait were noted. Other studies $[8,19]$ demonstrated decrease of stride width during gait and toe-off phase duration and increase of swing phase duration in children with spastic diplegia aged 6 to 10 years after three-week treatment using Adeli suit. The present study differed from research mentioned above by its longer duration and younger age of children as well less intensive therapy. Another study compared the effect of the conventional therapy program and modified (individualized) therapy with Adeli suit in $36 \mathrm{CP}$ children [15]. It was found that in case of modified therapy where the child was guided to use more functional and primary-task movements and exercises, the treatment effect was better as compared with the conventional therapy programme. 
A special physical therapy programme using the NOPS Atlant has been elaborated for children with a more enhanced level of CP in Kazan University of Medicine by Isanova [11] but the proposed programme could not be used in the studied group of preschool children with moderate-level CP. Therapy using the NOPS Atlant is based on individual tasks. This aspect supports the study of van den Broeck et al. [21], where gait and mobility in 3-10 year-old children was analysed. The authors found that individual training programme is most effective for improvement of spastic muscle function and gait characteristics [21].

One factor influencing the results of the study could be a number of therapy sessions per week. According to Isanova's results [11], maximum effect of the therapy with the NOPS Atlant is attained in case it is applied for three times per week and additionally in home environment. In the present study it was not possible to give Atlant suits for home use because the parents had not performed a course of therapy rules.

The present study had some limitations. The number of subjects was small, due to having to consider numerous criteria for including the subjects in the study. On the other hand, it decreased the homogeneity of the studied group. The therapy process was planned during a 3-month period with children participating twice a week, however, diseases or other reasons caused frequent absence of children from therapy lessons. The total time for physical therapy lesson was 40 minutes and the time of wearing the NOPS Atlant increased gradually in accordance with methodology, but we did not compare data with groups of CP children with lower limb spasticity who did not receive NOPS Atlant therapy.

In summary, children with spastic CP demonstrated significant improvement of range of motion of hip joint abduction, decrease of knee joint external rotation, as well as changes in foot progression angle during gait. Motor function re-activation during gait (lengthening of stride) in preschool children with spasticity caused by cerebral palsy was noted after 3-month therapy using the NOPS Atlant. However, future research is needed to elucidate mechanisms of neurodynamic therapy effect on motor ability in children with CP.

\section{ACKNOWLEDGEMENTS}

We wish to thank Andrey Averyanov and Vladimir Zotov, representatives of JSC Scientific-and-research union "Dynaforce" for possibility to use neuroorthopaedic pneumosuits Atlant in children physiotherapy. Also authors are grateful to Ms Mare Vene for language correction. 


\section{REFERENCES}

1. Bache CE, Selber P, Graham HK. (2003) The management of spastic diplegia. Current Orthopaedics, 17: 88-104

2. Bailes AF, Greve K, Schmitt LC. (2010) Changes in two children with cerebral palsy after intensive suit therapy: a case report. Pediatr Phys Ther, 22: 76-85

3. Brütsch K, Schuler T, Koenig A, Zimmerli L, Koeneke SM, Lünenburger L, Riener R, Jäncke L, Meyer-Heim A. (2010) Influence of virtual reality soccer game on walking performance in robotic assisted gait training for children. J Neuroeng Rehabil, 7: 15

4. Damiano DL. (2009) Rehabilitative therapies in cerebral palsy: the good, the not as good, and the possible. J Child Neurol, 24: 1200-1204

5. Davis RB, Ounpuu S, Tyburski D, Gage JR. (1991) A gait analysis data collection and reduction technique. Hum Movement Sci, 10: 575-587

6. Gage JR, Schwartz MH. (2009) Consequences of brain injury on musculoskeletal development. In: Gage JR, Schwartz MH, Koop SE, Novacheck TF. (Eds) The identification and treatment of gait problems in cerebral palsy. 2nd ed. London: Mac Keith Press, 113-114

7. Gapeyeva H, Mitt P, Ereline J, Pääsuke M. (2013) Influence of 3-month therapy using the neuro-orthopaedic pneumosuit Atlant on gait characteristics in preschool children with spastic cerebral palsy. 6th Baltic Scientific Conference "Sport Science for Sustainable Society”, 23-25 Aprill, 2013; Abstracts. Riga: Latvian Academy of Sport Education, 133-134

8. Gapeyeva H, Nugis H, Kallaste R, Ereline J, Pääsuke M. (2012). Influence of 3-week Adeli suit therapy on postural stability and gait characteristics in prepubertal children with spastic dyplegia. In: BALCONE 2012 Programme and Abstract Book: The 7th Baltic Congress of Neurology; Tartu, Estonia; May 9-12, 2012. Tartu, Estonian Ludvig Puusepp Society of Neurologists and Neurosurgeons, 163

9. Gormley ME Jr. (2001) Treatment of neuromuscular and musculoskeletal problems in cerebral palsy. Pediatr Rehabil, 4: 5-16

10. Harvey A, Rosenbaum P, Hanna S, Yousefi-Nooraie R, Graham KH. (2012) Longitudinal changes in mobility following single-event multilevel surgery in ambulatory children with cerebral palsy. J Rehabil Med, 44: 137-143

11. Isanova VA. (2010) New innovative medico-social technologies in rehabilitation of patients with motion and cognitive impairments. Kazan: Kazan State University of Medicine (In Russian)

12. Katz A, Tirosh E, Marmur R, Mizrahi J. (2008) Enhancement of muscle activity by electrical stimulation in cerebral palsy: a case-control study. J Child Neurol, 23: 259-267

13. Kochuneva OY, Zotov VA. (2010) Kinesiotherapy of locomotor dysfunctions using the neuro-orthopaedic pneumosuit Atlant. In: BAR 2010: 7th Congress of Baltic Association for Rehabilitation, Abstracts; September 17-18, 2010, Tallinn, Estonia. Tallinn: Estonian Society of PRM, 61 
14. Lance JW. (1980) Pathophysiology of spasticity and clinical experience of baclofen. In: Feldman RG, Young RR, Koella WP (Eds) Spasticity: Disordered Motor Control. Chicago, London: Year Book Medical, 185-203

15. Mahani MK, Karimloo M, Amirsalari S. (2011) Effects of modified Adeli suit therapy on imprvement of gross motor function in children with cerebral palsy. J Occupational Ther, 21: 9-14

16. Mutlu A, Krosschell K, Spira DG. (2009) Treadmill training with partial bodyweight support in children with cerebral palsy: a systematic review. Dev Med \& Child Neurol, 51: 268-275

17. Reid SM, Carlin JB, Reddihough DS. (2011) Classification of topographical pattern of spasticity in cerebral palsy: a registry perspective. Res Dev Disabil, 32: 2909-2915

18. Rodda JM, Graham HK, Carson L, Galea MP, Wolfe R. (2004) Sagittal gait patterns in spastic diplegia. J Bone Joint Surg (Br), 86-B: 251-258

19. Rõõs H. (2008) Influence of Adeli suit therapy in 6-10 year old children with spastic diplegia. Thesis of Master Study, Tartu: University of Tartu (In Estonian).

20. Sologubov EG. (1997) System of Rehabilitation in patients with cerebral palsy by method of dynamic proprioceptive correction. Thesis of Doctoral Study. Moscow (In Russian).

21. Van den Broeck C, De Cat J, Molenaers G, Franki I, Himpens E, Severijns D, Desloovere K. (2010) The effect of individually defined physiotherapy in children with cerebral palsy (CP). Eur J Paediatr Neurol, 14: 519-525

22. Woo R. (2001) Spasticity: orthopaedic perspective. J Child Neurol, 16: 47-53

\section{Correspondence to:}

\section{Helena Gapeyeva}

Institute of Exercise Biology and Physiotherapy,

University of Tartu

Jakobi 5, 51014 Tartu, Estonia

Tel./fax: +372 7376286

E-mail: helena.gapeyeva@ut.ee 